\title{
STRENGTHENING SUPPLY CHAINS FOR A SUSTAINABLE HOUSING SECTOR IN NEPAL: FACTORS INFLUENCING THE ORGANIZATION, MANAGEMENT, RELATIONSHIPS AND THE ADOPTION AND USE OF GREEN PRACTICES, PRODUCTS AND SERVICES
}

\author{
Ogenis Brilhant ${ }^{1}$, Somesh Sharma ${ }^{2}$, Swati Pujari ${ }^{3}$, Neha Shrestha ${ }^{4}$, Amit \\ Bajracharya $^{5}$ and Anita Adhikari ${ }^{6}$ \\ ${ }^{1}$ Energy and Infrastructure Management, Institute for Housing and Urban Development \\ Studies (IHS), Erasmus University, Rotterdam (EUR), The Netherlands \\ ${ }^{2}$ IHS, EUR, The Netherlands \\ ${ }^{3,4,5,6}$ UN-Habitat, Nepal
}

\begin{abstract}
EU's main approach to sustainable housing is promoting green practices/products within the building construction sectors SCs. EU Switch Asia program financed research conducted in Nepal, 2015, to understand the organization of SCs, identify factors/barriers affecting SCM and existing relationships, the reasons to adopt green concepts/approaches and recommend support for SMEs to strengthen the sector's management and sustainability. 109 companies, non-probabilistic snowball sampling and semi-closed questionnaires used in the survey. Conclusions: Companies create SCs to increase customer satisfaction, maintain long-term sales and retain clients. Size of company influences SCs organisation, SCM and using/producing green products/services; majority of participants had a person in the company to manage SC's and had very good knowledge of SC, SCM and greening issues. SMEs need support with: information/communication technology, promotion and improvement/development of green products/services. Government should: increases awareness of green building products/services; develop financial green incentives and simplify administrative procedures to buy solar products.
\end{abstract}

\section{KEYWORDS}

Sustainable housing, Green Supply Chain Management, SC's relationships, green practices and products, barriers

\section{INTRODUCTION}

The housing sector in this research focused on the building construction sector, which includes both residential and commercial buildings, that consumes huge amounts of natural and anthropogenic resources. This high consumption intensity makes the sector a key target to promote green approaches within the sector by adopting Sustainable Consumption and Production principles (SCP). A well planned, implemented and managed housing sector can act as an important enabler to promote sustainable development and simultaneously address the need for DOI: $10.5121 /$ ijmvsc. 2017.8101 
buildings and infrastructure in the cities [1]. The EU's approach to improve sustainability in the housing sector (in this research called "greening the housing" sector) is led by promoting SCP though a higher uptake of green products, practices and green services within SCM of the building construction sector. Greening the housing SCs is also being pursued in transition and developing countries.

This paper is based on the EU funded research SWITCH-Asia project, aimed at promoting sustainable production and consumption in Nepal's housing sector through the SCs of local Small and Medium Enterprises (SMEs). The research was jointly carried out by UN-Habitat, Nepal and IHS, EUR.

The development of a building goes through several stages including design, procurement of materials, and construction. Each stage involves a set of several actors who operate within their own SCs. Configuration for example involves several actors making the building construction sector fragmented and complex. In an attempt to simplify these complex SCs, a study conducted by the UNEP in 2014 divided the building construction sector into two broad parts (1) building delivery and management process (including housing concept, design, construction and end of life), and (2) the materials SCs (including material SCs that are organised to provide the construction site with the needed materials, products and services to build houses/infrastructure) [1]. This research paper focuses on the second part of the building supply chain model as described by Antink [1].

The research was conducted in 2015 in 3 cities in Nepal (Katmandu, Pokhara and Dahran). The research aimed to (1) understand how SCs of a selected number of companies from the building construction sector are organised, (2) identify factors affecting the management of these SCs, (3) identify and understand the existing relationships within these SCs in a business to business relationship from the supplier's perspective, and more specifically (4) identify the reasons that led these companies to adopt green practices, products and services, the barriers and factors hindering the development and the use of these green practices, products and services, and to recommend what external support SMEs need to strength the sector's management and sustainability.

Green housing products, practices, materials and services defined in this research as those products, practices, materials and services that deal with increasing energy efficiency and the use of renewable energy sources in buildings; increasing efficiency in water supply, Solid Waste Management (SWM), wastewater management services and using natural, renewable materials or contains minimally processed products. Consumers/clients in this study are defined as those actors in the SCs that can buy or use green products and/or services related to the construction, maintenance or upgrading their houses. They can be contractors, constructors, distributors, suppliers, producers, retailers, engineers, architects, customers and representatives of private associations such as the chamber of commerce, architecture and engineer associations and representatives of public organisations responsible for housing policies, regulations, certifications, etc.

The literature review revealed that issues related to this paper had not been extensively studied especially in case of developing countries, thus an extensive review of the basic theoretical concepts about organisation of SCs, relationships, SCM practices and the use of green products and services in order to prepare a research proposal more adapted to the Nepal conditions was conducted. Sections 2-4 provide a theoretical review of the main concepts on which the methodology and approach for this research was based. 
Section 2 reviews the fundamentals explaining the organisation and management of SCs including the concept of GSCs; section 3 focuses on relationships between various actors in the $\mathrm{SC}$ and section 4 reviews specifically the Housing (building construction) sector SC. Based on the findings from the literature a research design was developed which is discussed in section 5, followed by the research findings in section 6 . The conclusion provides systematic insights about organisation and the management of the housing (building) sector SC in Nepal, how the SC is influenced by the inter-relationships between various SC actors, the green products, practices and services being used, the factors and barriers affecting the overall SCM and recommendations how to strengthen the use of green products/services within these SCs.

\section{SC, SCM AND GREENING SCM (GSCM)}

\subsection{Supply Chain (SC) and Supply Chain Management (SCM) definitions}

Definitions of SCM differ between authors. Ross [2], views SCM as the act of taking organisations in a SC and develop integration by, establishing trust, reducing the distance between firms by improving communications, engaging early collaborative engagement and finally by alignment of systems and processes. Handfield [3] , defined a SC as essentially a series of linkages between suppliers and consumers until products reach the ultimate costumer and Mentzer, et al [4], defined a SC as a set of three or more entities (organisations or individuals) directly involved in the upstream and downstream flows of products, services, finance and information from a source to the customer. What is common to all of these definitions is that there is a flow of products services, information and finance from the suppliers to the costumers. From these studies and others we can conclude that an SC can exist even if there is no management of the elements which are referred to as distribution channels. SCM however requires overt management efforts by the organisations within the SC. [2, 3, 4]

\subsection{Reasons to Adopt SCM and Factors Affecting SCM}

Many factors may lead a company to decide to adopt the concept of SCM. Quezada et al [5] and de Sousa Jabbour et al [6] mention factors such as; company size, company environment, government support, environmental uncertainty, information technology, communication and planning tools, inadequate information sharing, lack of trust, lack of managerial commitment, constraint resources etc. They can be grouped in the following broad categories; factors affecting the adoption (creation) of a SCs; factors affecting the management of SCs; and factors affecting the relationships within these chains. De Sousa Jabbour [6] states in his article that large companies are more likely to adopt a SCM concept than SMEs and that companies are more likely to adopt SCM concepts if they are partners of large customers or other organisations.

\subsection{Green Supply Chain Management (GSCM) and Sustainability}

Companies under pressure of stakeholders, investors, customers and non-profit organisations push to include sustainability and green issues within their SC. This process of including sustainability into SCM is referred to in this article as greening SCs. GSCM practices for Tseng et al [7] refers to the responsibility of industries and enterprises to ensure coordination for environmental, social and ethical compliance throughout all SCs. He also defines GSCM as the combination of environmental thinking encompassing product design, material sourcing and selection, manufacturing processes, delivery of the final product to the consumer, and end-of-life management of the product. GSCM can reduce environmental impact through improved energy 
efficiency measures and the reduction of waste and pollution along the SC. It focuses on how firms utilise their suppliers' processes, technology and capability, and integrating environmental concerns to enhance its competitive advantage.

\section{RELATIONSHIPS IN A SUPPLY CHAIN}

The term relationships or partnerships refers to: strategic relationships, tactical relationships, transactional relationships, collaborative relationship, internal relationships etc. The management of these relationships affects all areas of a SC and has an important impact on the performance of a company. It is very often said that SCM is directly related to relationship management, which includes suppliers and customers.

Relationships between parties or partnerships, are seen in the literature as a commitment between the client and supplier, cooperating to meet separate but complementary objectives [8]. They argue that partnership approach results in greater accuracy, speed and flexibility in responding to consumer and environmental demands, development of new technology and products as well as more cooperation in maximising profits at a chain level. When trying to identify the main actors and relationships within a SC, two important factors should be considered: The definition of the end user/customer/buyer and determining if the study focuses on suppliers' or the customer's perspective. When focusing on the suppliers' perspective, the business to business relations between a supplier and its main customers are considered most important, while when the focus is on customer's perspective the relationship between a seller and the client/consumers are considered most important.

\subsection{Factors Leading to Creation and Success of Relationships}

Many factors can contribute to the establishment and the success of the partnership in a SC. Renko [9] pointed out that the driving factors for forming partnerships are cost reduction and better customer services followed by supportive corporate factors that encourage partnerships, such as having a similar management style, compatibility of operations, and the joint activities and operations used to build and sustain the relationship, such as communication channels and investments.

Companies create SCs in order to facilitate the achievement of their own goals, improve performance and to satisfy their customers. The essential element of a SC is the degree of collaboration among their members. This collaborative way of organising a SC brings several benefits for the company such as an improvement of the flow of materials throughout the chain, increased speed of the deliverables, reduced stock levels and providing quick responses to customer changing demands. Renko [9] defined collaboration as two or more companies sharing the responsibility of exchanging common planning, management, execution, and performance measurement information, collaboration is the ultimate step of a relationship within a SC. For Bowersox et al [10], the driving force underlying the emergence of collaborative relationships among firms in a SC is the recognition of mutual dependences. When a firm acknowledges dependency with its suppliers and/or its customers, the stage is set for cross-organisational collaboration. The degree to which dependence is mutually recognised and acknowledged by all parties in the relationship defines the nature of the resulting relationship. 
International Journal of Managing Value and Supply Chains (IJMVSC) Vol. 8, No. 1, March 2017

\subsection{Trust and Relationships}

Developing trust on both sides of a relationship (partnership) is the critical factor to success in a SC relationship. Bowersox et al [10], affirms in his article that no real collaboration can exist in $\mathrm{SC}$ relationships without meaningful trust. He explains that while a powerful firm may be able to influence the behaviour of a less powerful organisation, the change in behaviour may be temporary and certainly entered into unwillingly. Research shows that issues such as technology compatibility, information exchange, and appropriate measurement systems are all key issues to be resolved in collaborative alliances, the human behaviour issues related to culture and trust are very important and much more difficult issues to solve. According to Petrovic-Lazarevic et al [8] trust is linked to bonds/ties. For him while structural bonds are important to any business relationship, those organisations that have strong social bonds generally have a greater commitment to their relationships

While several types of trust exist, a meaningful way to understand trust in SC collaboration according to Bowersox et al [10], is to distinguish between reliability-based trust and characterbased trust: Reliability-based trust is grounded in an organisation's perception of a potential partner's actual behaviour and operating performance. Essentially, it involves a perception that the partner is willing to perform and is capable of performing as promised. If SC participants cannot rely on partner performance as promised, all efforts to develop collaborative relationships fail. Character-based trust is based in an organisation's culture, leadership, and philosophy. Essentially, it stems from perceptions that SC partners are interested in each other's welfare and will not act without considering the action's impact on the other. When this aspect of trust is developed, participants do not feel vulnerable to the actions of one another. Trusting partners believe that each will protect the other's interest.

\section{THE HOUSING (CONSTRUCTION) SECTOR AND SCM}

The housing (building construction) sector is fragmented, it includes all the activities needed to create any type of building or other fixed structures. Many of these activities are carried out before the materials and components arrive at the construction site. Working at the construction site is only the last stage of the production process. The sector is also characterised by long SCs starting with the formulation and specification of product delivery. It also includes many actors such as contractors, subcontractors, architects, engineers, retailers, clients etc. The subcontractor in general consist of SMEs.

Koçtaş [11] studying the construction sector found that the sector has important different characteristics compared with the other sectors: 1-Uniqueness (every construction project is a one-off, clients have different needs and priorities, the construction sites have unique conditions (ground, climate, surroundings), buildings and other structures are usually made to meet individual customer requirements, inducing innumerable architecture designs and sometime tailor made solutions; 2- Site production (construction production is carried out at a construction site which is unique for every building, they can be temporary, involve more than one organisation and construction is a project based production and in every project, project- specific teams are assigned; 3- Regulatory intervention (regulations and laws about construction are usually countryspecific or territory-specific. He also mentions that the sector is characterised by various practices and disjointed relationships very often result in transient relationships rather than long term risk sharing partnerships. He pointed out that these disjointed relationships make the construction SC work as a disparate collection of separate organisations rather than a unified team. The SCs of the 
building and construction sector suffer from lack of integration and as a consequence, there is a lack of trust between construction clients, designers, main contractors and suppliers.

Charter et al [12] in a study conducted in the UK found that the construction chain starts with the clients who usually engage engineers and architects as the designers in a construction project. They, in turn, hand the construction activity over to the construction managers. The construction managers may hand the construction project over to contractors, or they may be the contractors themselves. O'Brien [13] compared the building construction supply organisation with the manufacturing sector and found that both sectors are organised in a very similar way however the building construction sector contains some specific characteristics. According to him, both sectors consist of different parties which are connected via transactions, sourcing, information flows and funds.

\subsection{Greening the Housing SCs}

One central element to promote the greening of the housing SCs is the identification and exploration of green interventions that can or could occur in both the building delivery and management process and the material SCs. UNEP has created a project called Greening the Building Supply Initiative to identify and explore these interventions [1]. For the purposes of this initiative, green interventions are defined as regulatory and control mechanisms, economic or market-based instruments, fiscal instruments and incentives, and support, information and voluntary actions, taken by stakeholders in the SC, that lower the environmental impact of a building, its materials or building-related activities over the life-cycle of the building, and/or have a wider or legacy environmental, social or economic impact beyond the building itself. The key building sectors elected to identify and explore the opportunity for green interventions in this report are energy, carbon, materials, waste and water. Among the diverse actors involved in greening SCs of the housing sector, the suppliers play maybe the most important role [1]. The selection of suppliers is thus a key issue in managing a GSCM as they play an important role in its implementation. Singh et al. [14] recommends that all conventional SCM criteria including performance, need to be incorporated together with environmental criteria to find the most suitable supplier. He proposed six GSCM dimensions that must be addressed during this selection process: a) green manufacturing and packaging, b) environmental participation, c) green marketing, d) green suppliers, f) green stock, and g) green eco-design.

\subsection{Defining Green Housing Materials, Products and Services}

The construction, renovation, maintenance and operation of buildings accounts for very large quantities of materials which are extracted from nature, processed, used and ultimately discarded. The opportunities to reduce the environmental and health impacts of the housing sector involve important big decisions such as location, to small decisions such as paint and light bulbs. The products we use to clean, light, furnish, renovate, and build our homes must also be a part of the greening process. Reducing their environmental impacts requires thinking and learning about not just how we use products, but where they came from and where they are going. Important factors to be considered in this process are: Energy used to make, transport, and use a product; The product's contents and the sources of its raw materials; Emissions during manufacturing the product, and the level and type of toxins in the final product; and The product's durability (lifespan) and recyclability.

Defining what a green product, material or service is, has proved to be difficult and very challenging. As a result, until this moment there no word wide official accepted definitions of green products or service. According to Prasad [15], the greenness of products is defined through 
various attributes. These could be environmentally focused in terms of materials used, energy consumed or pollution generated. These attributes are reflected in different stage of the life cycle - before usage, during usage or after usage. He also defines green products, materials or services as those having reduced environmental impact, over its life cycle. For the USA Environmental Protection Agency (EPA) a product may be considered "greener" if scientific evidence demonstrates that human health or environmental impacts have been significantly reduced in comparison with other products that serve the same purpose.

Several tools and or guides using different approaches exist which try to measure how green a building material, product or service is. One of these approaches found in many of these tools and guides is to check if the examined product, material or service contains the green characteristics (attributes) used by the tool or guide. Voluntary instruments such as green labels and green procurements also use this approach. In Europe, the UK on line tool called The GreenSpec Guide to Residential Building Materials [16] lists over 2,200 environmentally preferable products, with key insights on the green attributes of each product and the most critical green issues for each product category. The directory is divided into 5 areas with each area containing a set of standards and their respective definition. This research has selected a set of these green attributes to define a green product, process, material and service. They are summarised in the boundaries of the research which were mentioned in the introduction.

\subsection{The Housing Sector in Nepal and the Green Issues}

The construction sector is a major sector for the Nepali economy. It consists of a few large and a lot of small construction companies. According to the Federation of Contractors' Associations of Nepal, the sector contributed around $10-11 \%$ to the GDP and it uses around 35\% of the government budget.

In recent years according to Rajbhandari [17] citing results of the National Census of 2001, Nepali cities have experienced an accelerated process of urbanisation. This rapid urbanisation process is increasing the deficit of dwellings in Kathmandu and in other cities, and putting a huge pressure on the national government and the construction sector to provide enough and better housing facilities. According to Rajbhandari the Nepali housing sector has several problems, and one of the most important is the poor building safety structures which makes the sector more vulnerable to the recurrent earthquakes. He also said that according to the Nepal Living Standards Survey (NLSS) 23\% of the urban households fall below poverty line, compared to $44 \%$ rural households and $42 \%$ Nepalese as a whole. This study indicated that because of this level of poverty, people cannot consult structural engineers to design earthquake resistant structures. They construct their houses with the help of local labour contractors, who themselves do not know sufficiently about the construction of safe structures. Moreover, due to a low budget, they are forced to use low quality construction materials, resulting in the construction of weak structures.

As Nepali economy is growing, an emergent middle class has started to appear. The concept of sustainable housing and green homes/buildings are beginning to gain importance and space into the national and local government agendas. Recently the Nepali government adopted two important policies linked to the field of sustainable housing: a draft of a National Shelter Policy and the National Climate Change Policy to promote green technologies with low carbon footprints. There is also a proposal in discussion to update the national building code to embed sustainable and green practices. 
Very little or practically no information however exists regard the organisation of the construction sector and their SCM practices as well as the green practices, products, materials and services being used in these SCs.

\section{Methodology AND ReSEARCh DeSign}

The research adopted a deductive approach using what is already done and known in the research topic and the necessary theories applied to the topic in order to guide the formulation of the objectives. The unit of analysis are private companies involved with the construction and reform of commercial and residential houses in three cities in Nepal: Kathmandu, Pokhara and Dharan. Descriptive and explanatory types of research were used in the study. These choices were motivated by the objective of the research to understand the organisation and the factors affecting the relationships of the SCs of a selected number of construction companies.

The research used a cross-section approach to collect data at a single point in time and qualitative and quantitative methods to collect the data. The choice to use qualitative and quantitative methods was justified by the types of the objectives of this research. A non-probability sampling approach was adopted in the research, this choice was motivated by the difficult to know (estimate) the research population of the study. The study population consisted of the total number of private companies and organisations involved in the construction of commercial and residential buildings which included the companies dealing with green house products and services in the three chosen cities.

Consumer(s) or client(s) for this study were defined as those actors in the SCs that can buy or use green products and or services, in the case of this study the consumers were the respondents of the questionnaires and interviewees that were also representative of the companies and also actors of the SCs. Examples of these actors and consumers of this study are contractors, constructors, distributors, suppliers, producers, retailers, engineers, architects involved in the companies SC as well as representatives of private associations (chamber of commerce, architecture and engineer associations) and representatives of public organisations responsible for housing policies, regulations, certifications, etc.

\subsection{Data Collection}

A survey strategy was adopted for data collection. Three types of research instruments were used in this study: group discussion (referred to here as a workshop with local stakeholders), interviews and questionnaires. This workshop was also used to pre-test the questionnaires and to identify the key companies to start the process data collection.

A snowball sampling approach was used to collect data to study SCs. The process of data collection started by selecting a short number of constructors or distributor companies dealing with the construction sector and used these companies to identify their suppliers and the suppliers of this and so on.

Semi closed questionnaires and interviews were used in this research. Semi closed questionnaires were used to collect quantitative data about the SCs organisation, actors, relationships and perception on green issues and green products. They were developed using the literature review information and applied using a paper face to face approach. The questionnaires consisted of two types of questions: type one consist of a semi-closed list of options linked to the subjects being 
investigated which were presented to the respondents that depending of the kind of subject should choose only one option or in some other situations more than one. Type two consisted of 5-point Likert scale where respondents were asked to indicate in this scale the extent to which they strongly agree ( 5 on the scale) or strongly disagree ( 1 on the scale) with the statements drawn from the literature. The content of the interviews were prepared after a preliminary assessment of the results of the questionnaires which had being conducted. This approach was used in order to have the opportunity to retrieve in-depth information on certain issues that were not clear enough and to address new important issues that had not been covered by the questionnaires. The interviews applied to the public authorities, key experts from the university and the private sector contained the same type of semi closed and opinion questions and included a set of open questions on particular issues such as policies, incentives, the role of the government organisations and social civil organisations in promoting green issues within the construction sectors. This guided standardised approach used for the interviews did not limit the way in which each question could be answered but helped to make a straightforward comparison with the answers of the questionnaires and it also helped to focus on the essential aspects of the research.

The target respondents for answering the questionnaires in the companies were the managers of the environmental department or the managers in charge of buying and/or marketing products and materials within the company. If there was no manager, the owner or the person (employee) who knows most about how the company works was chosen to do the questionnaires or the interviews. The interviews were applied to the head of sections or departments of public and civil organisations.

\subsection{Sampling Design}

Primarily a total sample of 150 respondents were chosen; 100 in Kathmandu and 25 in each of the other cities. This number was unfortunately not achieved due to the earthquake that happened during the period of data collection. As a result of this problem a total sample of 109 questionnaires (companies) were filled in: 59 in Kathmandu valley, 26 in Pokhara, and 25 in Dahran. Six interviews were carried out with officials, government representatives, and civil societies associated with the housing sector. In big companies the target respondents were the managers of the environmental department or the managers in charge of buying and or marketing products and materials within the company. If the respondent organisation had no manager, the owner or the person (employee) who knows most about how the company works was chosen as respondent to the questionnaires or the interviews. In general with small companies, the owner or another important person of the company was chosen.

\subsection{Limitations of the Study}

One of the fundamental limitations was adopting a non-probabilistic sampling approach, which implies a relatively small sample size, and does not guaranty a good representation of the studied population. This means that the results obtained with this research cannot be generalised but are more likely to be a representation of the situation of the cities at the moment the data was collected. All the questions in the questionnaires and the interviews were drawn from the international literature, there were a limited number of articles found on studies concerning the organisation of the building construction sector and their SCs. Although this approach is a relevant one with regard to academic purposes, it may not have taken into account important local factors such as those linked to the local cultural values that may influence the organisation and the relationships within the SCs, the involvement of employment in the process of production of green products, the types and the methods of producing green products, etc. The questionnaires 
were in English, which very often needed to be translated by the applicant to the respondents which may have had a substantial influence on their choices.

\subsection{Generalisation, Reliability and Validity}

While using a non-probabilistic sampling approach it is difficult to generalise the results. The sample collected did not take into account the whole population (stakeholders) involved with sustainable housing in the three chosen cities but a small sample of them selected using the research criteria. Although for overcoming this limitation we designed the structure and operationalisation of data collection process in a way that enabled it to include a fair sample of different stakeholder functions, ages and gender in order to get a good sample representation.

In this study internal reliability was assured by applying Cronbach's alpha test to the scale variables. In this test, the alpha parameter ranges from 0 to 1 , in which 0 means completely unreliable and 1 means perfectly reliable. A score of more than 0.5 is an acceptable reliable value. The reliability was also assured by formulating the questions using the information obtained in the extensive literature review, where articles, theories and concepts linked to the topics were analysed and by properly phrasing the questions so that they were not misinterpreted or ambiguous. Validity of the data collected was also assured by pre-testing the questionnaires with a group of ten local stakeholders submitting the revised questionnaires to two competent and specialised experts on sustainable housing issues before the final version was given to the respondents.

\subsection{Data Analysis}

Data from the interviews and questionnaires were coded and analysed using the Statistical Package for Social Sciences (SPSS 20). Outputs included descriptive statistics such as Frequencies, Means and Percentages. SPSS 20 was also used to generate the inferential statistics like the Cronbach's alpha test applied on the scale variables to indicate their internal reliability. Along with analysing frequencies specific statistical methods ANOVA (ANalysis Of VAriance), paired t-test and Chi square were applied to analyse specific indicators where comparison of means was an appropriate method for explaining the results. In data analysis a confidence interval was kept at $95 \%$ with a level of confidence of 0.05 .

\section{FINDINGS AND DISCUSSIONS}

The findings and discussion were structured in 4 parts: Part 1 dealt with the company (respondents) demography; Part 2 SCs organisation and SCM aspects; Part 3SC relationships and Part 4issues related to GSCM procedures including green practices, products and services.

\subsection{Company Demographics}

A total of 109 companies were contacted in this research. Kathmandu (60 questionnaires), Pokhara (25 questionnaires), Dahran (24 questionnaires) and six (6) interviews with different public and civil society organisations. The majority of the respondents who answered the questionnaires and interviews were male (94\%) and only $6 \%$ were women. $54 \%$ of the respondents were aged between 21-40 years old while $44 \%$ were between $41-60$ years old. The vast majority of the respondents $(80 \%)$ had a bachelor's degree, $60 \%$ had a post graduate degree, and $12 \%$ had a school diploma. $93 \%$ of the responders declared to have a middle income level, 
only $4 \%$ a high income and 3\% a low income. Six organisations were contacted for interviews: $57 \%$ were females, had an age between 41-60 years, had a post-graduate diploma and professed to have middle income.

These disproportional results between genders is often found in similar studies conducted in the building construction sector worldwide. One of the surprising results for this study was the high level of well-educated and relatively young mass of entrepreneurs and professionals found in this research. These results could be explained due to the fact that the target respondents of the research were the managers and or owners of the companies which belong in their vast majority to the middle class and have a middle income. These results can be seen as a good sign for the future of the construction sector in Nepal, as this young and educated mass of entrepreneurs are more receptive and are able to easily adapt themselves and their companies to the fast changeable market, technologies and consumers habits.

The ANOVA analysis and chi square test conducted to investigate possible influence of some demographics data on SCM and green issues gave no significant results under the confidence interval of $95 \%$ used in this study.

\subsection{SCs Organisation and SCM}

\subsubsection{Company size, type of companies and actors in the SCs}

The building construction SCs in Nepal are composed of, in its majority by small enterprises $(64.8 \%)$ which in this study were defined as those companies having a total staff of between 1 and 20 and total annual revenue of under $\$ 20,000$ US dollars (Table 1). The second most important group (28.7\%) were medium enterprises defined as those companies having 21-100 staff and revenue between \$1million to \$2million and the third group formed by the large companies (developers) defined as those companies have (more) than 100 staff and revenue above $\$ 259$ million) with $6.5 \%$. Per city the statistics showed that most of the small enterprises are based in Pokhara and Dahran with $77 \%$ and $76 \%$ respectively as compared to that in Kathmandu (55\%). The largest number of large companies were found in Kathmandu 9\%.

The majority of the contacted companies (40) in this research, were formed by manufacturing companies delivering diverse types of construction products and materials. The second group was formed by 31 construction or contractor companies, and the rest were traders and retailers of different sectors such as electrical, construction materials water, wastewater and others related products and services.

Table 1 Main actors in the SCs

\begin{tabular}{|l|l|}
\hline Main actors in the supply chains \\
\hline $\begin{array}{l}\text { Contractor, constructor, sub-contractors, designers, clients, suppliers and } \\
\text { distributors (retailers }\end{array}$ & $29.6 \%$ \\
$\begin{array}{l}\text { Constructor, sub-contractor, suppliers, clients } \\
\text { Contractor, sub-contractors, suppliers of the immediate supplier and clients of } \\
\text { the immediate clients }\end{array}$ & $22.2 \%$ \\
$\begin{array}{l}\text { Contractor, constructor, suppliers, and distributors } \\
\text { Others (specify) }\end{array}$ & $6.5 \%$ \\
\hline
\end{tabular}


International Journal of Managing Value and Supply Chains (IJMVSC) Vol. 8, No. 1, March 2017

As it is showed in Table 1, local SCs are composed of several types of actors. The statement consisted of the chains formed by contractor, constructor, sub-contractors, designers, clients, suppliers and distributors (retailers) with $29.6 \%$ was the most cited followed by the one called "others: and the one composed of a constructor, sub-contractor, suppliers and clients with $22.2 \%$. Using the classification of SCs proposed by Mentzer, et al [4] and in line with the results, it could be said that more than $50 \%$ of the SCs could be considered as having a middle length. On the other hand we also acknowledged that many other different compositions of SCs (28.7\%) may exist and possible with different lengths.

\subsubsection{Respondents' Understanding of Meaning of Concept (Definition) of SCs and SCM}

In general most of respondents have a good understanding about the meaning and or definitions of the SC and SCM among all companies contacted in this study. Possible explanations for these results could be that they are related to the high level of education of the respondents. The majority had a bachelor and or post graduate course, or the possible influence of the verbal translation of the questionnaires by the interviewers especially the small companies such as retailors and traders during the moment of the application. This mode of applying questionnaires is not recommended once the words used to make the translation as well as the tone of the voice of the interviewer could influence the choices of the respondents.

\subsubsection{Reasons to Create a SC}

Companies create SCs because they want to increase customer satisfaction ( $89 \%$ of the combined strongly agree and agree answers) followed by building trust among the suppliers (88\%), reduce the time of delivery (82\%), improving financial performance (79\%), improving quality (78\%) and reduce costs $(58 \%$. Differently from the literature $[6,9]$ which says that the size of the company and cost reduction are among the most important reasons to create SCs, this option obtained the minimum score among all proposed reasons (58\%). The factor that trust has appeared as the second most important motivation to create a SC may indicate that the companies give high priority to the relationships with their suppliers. This issue will be further explored in the section relationships.

\subsubsection{Staff Deployed to Manage SCs, to Buy Materials/ Products and Size of the Companies}

Most of the contacted companies (55\%), all sizes included (Table 2) have a special person to manage the SC while in $65 \%$ of these same companies were the owners of the company who were able to make decisions for buying materials and products $(65 \%)$ followed by the project manager with $20 \%$. In the same table we can also see that $45 \%$ of the companies do not have a special person to manage their SCs. However the fact that a slight majority (55\%) do have a special person indicates that also some small companies have a special person to manage their SCs. Only $35 \%$ of the total contacted companies were large/medium companies. This result can be seen as an important indication of the importance the companies are giving to their management of their SCs. In Kathmandu $60 \%$ of the companies have a special person to manage the SCs and the owner of the company is mainly in charge of buying material and products; in Dhahran $60 \%$ of the companies do not have anyone to manage the SC and in $84 \%$ of these companies the owner is in charge of buying material and products. In Pokhara 50\% of companies have one person to manage their SCs and in $60 \%$ of these companies the owner is responsible to buy products and materials. 
Table 2 show a situation that while the majority of the companies do have a person to manage their SCs this person is not in charge of buying materials and products which is decided by the owner of the companies. It needs to be added also that very often the owner of the company is also in charge of managing the SCs especially in SMEs. In discussing these results during one interview applied to the Nepal Association of Architects, the interviewer justified the existence of this situation by the fact that in Nepal it is very common that many small and medium building construction companies are owned by engineers that very often hire an architect to make the basic designs in order to comply with the legal requirements but the final decision on the sort of materials and buying of the materials and products belong to them (the owners).

Table 2 Dedicate staff to manage SC and who decides the purchase of materials and products

\begin{tabular}{|c|c|c|c|}
\hline \multicolumn{3}{|l|}{ Existence of a dedicated staff to manage your SC } \\
\hline \multicolumn{3}{|l|}{ Yes (55\%) and No (45\%) } \\
\hline Who is in charge for purchasing of materials and products in your SC? \\
\hline Contractors & $\begin{array}{c}\text { Project } \\
\text { manager }\end{array}$ & Owner/Proprietor & $\begin{array}{c}\text { Other (specify) } \\
\text { (client, designer, architect, } \\
\text { etc.) }\end{array}$ \\
\hline $4 \%$ & $20 \%$ & $65 \%$ & $11 \%$ \\
\hline
\end{tabular}

The results of the ANOVA analysis applied to the group formed by 55\% of companies that said to have a special person to manage their SC shows a significant ANOVA coefficient value $(0.001)$ which means that the size of the company influence the existence of a special person to manage the SC. Jabbour 2011 also found a similar result. Within this group, 87\% of the large and medium size companies (considered as a sub-group) have a special person to manage their SCs while in small enterprises this percentage drops to $32 \%$. In this same sub-group medium/large companies the owner of the company has a smaller influence on the decision to buy materials and products $(45 \%)$ than in the small companies $(75 \%)$.

\subsubsection{Factors affecting the management of the SCs, driving forces to improve SCM, and the size of the companies}

Information technology and the flow of information (Figure 1) with 92\% of the combined (agree and strong agree) choices is the top factor affecting the management of their SCs followed by communication and planning tools with $88 \%$ and the environmental uncertainty (understood as the market changes in relation with the clients views, preferences and behaviour regard to green issues) with $70 \%$. Market related issues were the top three most cited driving forces for improving SCM: product development in line with client demand (77\%) followed by increasing competition from other companies (69\%) and market development in relation to green issues with $64 \%$.

These driving related market issues could be seen as reflex of the fierce concurrence the Nepalese companies within the construction sector are having from the foreign construction companies, especially from the import of green construction materials, products and services as well as the fast change of the Nepalese consumers/clients with regard to the green issues and new technologies. 
International Journal of Managing Value and Supply Chains (IJMVSC) Vol. 8, No. 1, March 2017

Figure 1 Factors Affecting SCM

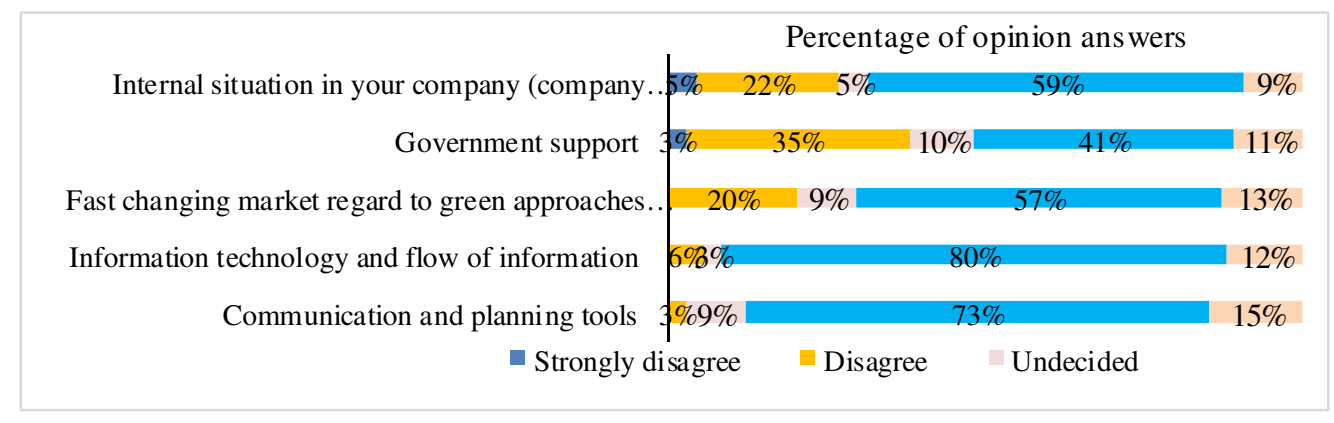

Per city, the factors were more less the same in Kathmandu and Dahran while in Pokhara the option government affects the management was more important than the environmental uncertainty

\subsection{SC Relationships}

\subsubsection{Type of Relationships, Reasons to Build up a Relationship, Factors that Guarantee a Successful Relationship and Main Ties (Bonds)}

Coordination of goods and services with suppliers distributors and clients is the most common type based relationship that exists in SCs of the contacted companies with $91 \%$ of the combined agree and strongly agree opinions, followed by strategic partnering which include a long-term relationship across many projects with $89 \%$ and collaborative relationship with suppliers, competitors and other SC actors with $86 \%$.

Contrarily to what was expected for a developing country such as Nepal, the results showed that the existing relationships within these SCs are more complex that the simple commercial (vendor) relationship or project level based relationship. However if we consider that most of the SCs within the Nepalese construction sector were considered as having a middle length (Section 6.2.1.) these types of more complex relationships may exist especially in the SCs of the big developers (large companies). Another possible explanation for the existence of these complex relationships could be the fact that the respondents did not know the correct difference between the terms collaboration and strategic partnering, or that they were influenced by the translation of the questions by the researchers or that they made their choices based mainly on the statements and did not apply them to their own companies situation.

Companies build up relationships among their suppliers in first place to maintain long-term sales (96\%) followed by keeping close contact between suppliers and clients (91\%), retention of suppliers and clients (88\%) and to improve the quality of products with $86 \%$ (Table 3 ).

Mutual trust, defined as the belief that a party's word or promise is reliable and party will fulfil its obligations, is considered by the companies as the most important factor to guarantee a successful relationship among their suppliers $(92 \%)$ followed by cost reduction and increasing profitability $(88 \%)$ and personal relations together with recognition of mutual interdependence and commitment ((desire to continue a relationship) with both $85 \%$. Per city these factors are approximately the same 
Table 3 Reasons to build up a relationship and factors to guarantee a successful relationship

\begin{tabular}{|l|c|}
\hline Reasons to build up a relationship & Percentage \\
\hline To get the cheapest price between supplier and client & 65 \\
To retain supplier and client & 88 \\
The necessity to maintain long-time scale & 96 \\
To keep close contact with suppliers and clients & 91 \\
To keep close contact with suppliers and clients & 86 \\
\hline
\end{tabular}

(Percentage is a combination of strong and agree opinions)

Although commercial and profitability issues are important reasons to build up relationships as well as important factors to guarantee the success of the relationships, companies also consider personal relations and social ties as very important factors to guarantee a successful relationship. Personal and social ties are for example more important than legal contracts and agreement ties in Kathmandu (58\% and $42 \%$ respectively). In the other cities legal contracts ties are slightly more important than the social ties.

\subsubsection{Barriers to Implement Relationships and Improving SCM}

Inadequate information sharing defined as lack of communication among the suppliers (83\%), constraints resources $(82 \%)$ and lack of integration between those who design and those who construct/deliver (79\%) are the most important barriers companies are facing to implement and improve their relationships of the combined strong agree and agree opinion. Lack of management commitment $(77 \%)$ followed by lack of trust, poor alliance, management practices $(68 \%)$ and difficulty of keeping the relationship overtime from one project to the other project (55\%) are the other cited barriers.

These barriers are very often found in other studies and in the case of the construction sector in developing countries such as Nepal where the habit of self-construction and a multitude of small construction companies, very often owned by an engineer exist, it is very difficult to integrate the design process with the construction and or deliver of materials. This barrier was also cited by the interviewers of the Nepal Association of Architects and of the Engineers as well as lack of communication among the partners very often motivated for technological and personal habits

\subsection{Greening the Building Construction SCM}

This section deals with several important green aspects of the SCs: meaning of the companies on green concepts, green advantages and attributes of product, material or service, driving forces for using green products, types of green products being used, top barriers and the factors that hinder the development and the use of green practices, products and services within these SCs.

\subsubsection{Understanding of the Companies on Green Concepts, Advantages and Attributes of Green Product, Material or Services}

The respondents have a very good understanding (meaning) of the green concepts, products and their advantages and costs in relation to the traditional products and materials. Statement such as "green buildings and green products are more environmental friendly than the conventional buildings and products," they promote conservation of energy, water and reduce wastes, they 
reduce water consumption and waste production, GSCM integrates environmental thinking (issues) into SCM, and that " green building certificate is a voluntary instrument to promote construction of more sustainable buildings have obtained more of than $90 \%$ of the combined strong agree and agree opinions.

Regard to the advantages and costs of green products and services (figure 2), the majority of the respondents have the opinion that green products cost more than the traditional ones and that using energy efficient systems can lead to an increase in initial building cost (76\%).

However an important number of respondents (strong disagree and disagree) with these results. $35 \%$ thinks that installing green features do not increase total costs and $27 \%$ that materials used for constructing green building and green features do not cost more than those for conventional buildings. Possible explanation for these cost related results are that they do not have knowledge about the costs of the green products or if they know they are considering the total cost taking into account the life time of the products or the building.

Figure 2 Understanding of the companies on the advantages and costs of green products, materials or services

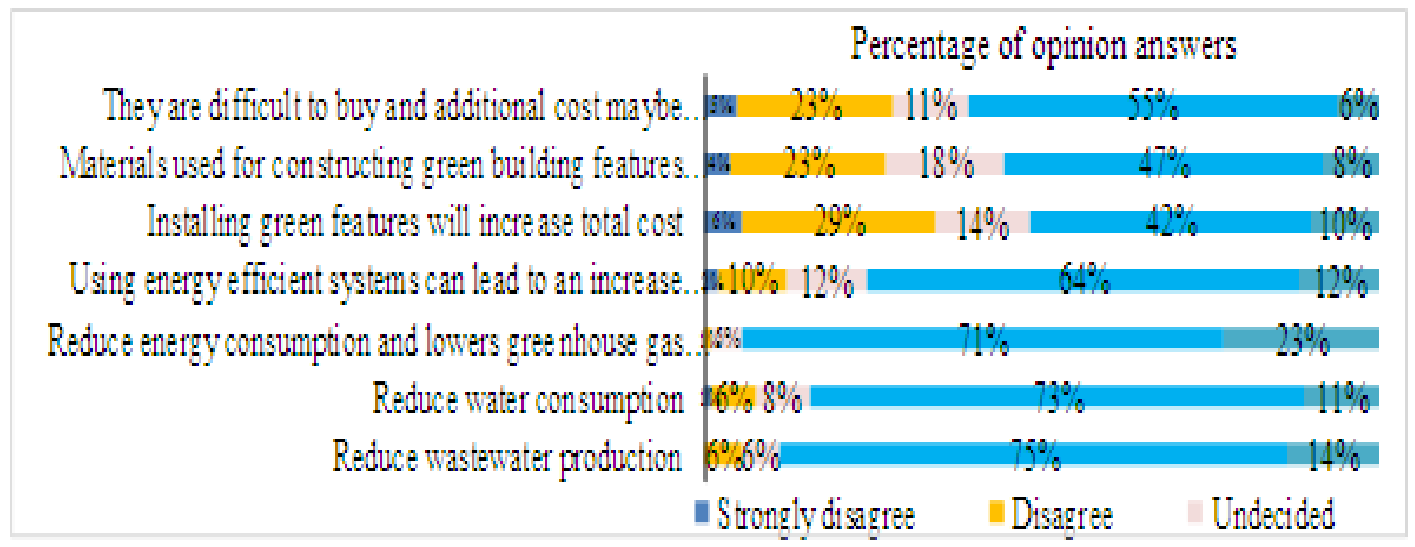

\subsubsection{Green Attributes of a Material or Product and Driving Forces Leading Companies to Adopt Green Practices, Products and Services in SCM}

Company's managers/owners have a very good knowledge of the attribute a product or services need to have in order to be considered green. All the statement containing attributes to characterise a green product or material obtained a very high combined strong and agreed scores. Attributes such as reducing wastes generation, energy and water consumption, heating and cooling loads, using renewable resources and free from toxic material scored above $90 \%$.

Corporate environmental and social responsibility (Figure 3) both with $92 \%$ considering the combined strong and agree opinion answers are the most important driving forces leading the companies to adopt green practices, products and services in their SCM. Attracting and retaining clients with $83 \%$ and improving company's image with $77 \%$ are respectively the third and fourth most import driving forces. Per city the results are more less the same. 
Figure 3 Driving Forces for Adopting Green Practices, Products and Services in SCM.

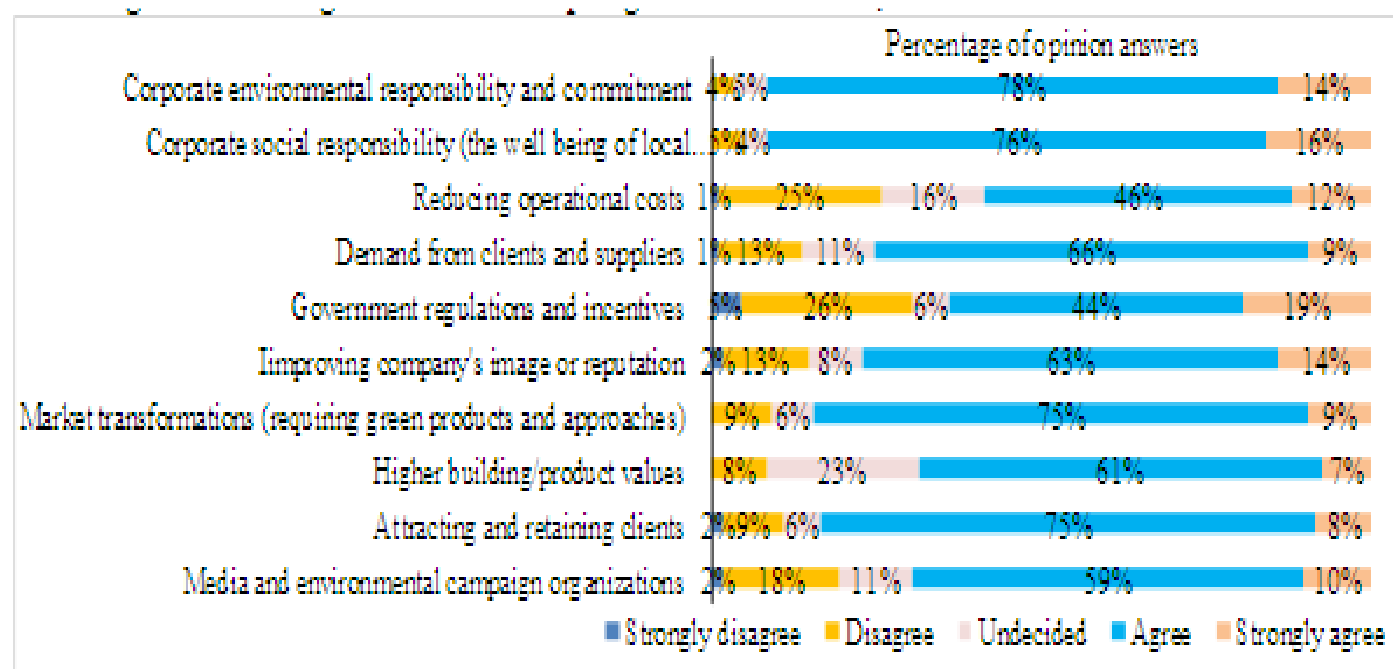

It is important to sign in these results that the most important driving forces leading companies to adopt green practices and product in their SCM are market related forces and not government forces. This is a good signal that companies are reacting to the market change in relation to green and social issues and are not waiting for the government.

\subsubsection{Green practices, products, materials and services being used, produced or sold, and the size of the companies}

$16 \%$ of all contacted companies were not using any green practices or including any green issues in the SC procedures and management. The big majority of the companies are using one or more green practices and waste (26\%) and water reduction (13\%) are two most common green practices being used followed by the use of environmentally friendly energy sources and green procurement with both $12 \%$, energy efficiency $(11 \%)$, green policies $(3 \%)$ and other $(2 \%)$. The fact that $12 \%$ of companies are adopting green procurement in their SC is somehow an unexpected result once we could not found any government or other NGO initiative promoting green procurements. Maybe this is just a spontaneous action of some companies to improve company's image or the answers do not know exactly what green procurements means.

24 companies out of the 109 contacted companies were producing or selling green products, materials and/or services. Out of these 24 companies, 8 companies were selling products or delivery services related to solar panels and other renewable energy appliances; 6 produced and sold hollow block cements, 4 produced and sold rain water harvest services and components, 3 companies produced and sold appliances related to solar water heating, 2 companies sold high insulated UPVC windows and one company produced and sold services linked to the generation of bio gases. Most of the companies dealing with solar panels and other energy appliances are traders (importers) or retailers while the companies dealing with rain water harvesting and sanitation are local manufacturers or assemblers and very often deliver some related green services. Hollow cement blocks, although not fulfilling the green attributes selected for this research, were considered as a local green product according to the local producers and experts as they consume less materials than traditional bricks 
These results showed that $22 \%$ of all contacted companies deal with green products or materials which indicate that there is already in place an important housing market for green products and services in the country, not only the construction companies are using these products but selfconstructors and householders are also using these products and services in their own houses.

The size of the company does influence the adoption of green practices. The ANOVA results showed that large and medium companies are those adopting more green practices

\subsubsection{Barriers and Factors Hindering the Development and the Use of Green Practices, Products and Services within the SCs}

From Figure 4 we can see that the barriers and factors hindering the development of the green practices, products and services in the contacted companies can be grouped in two types: market/consume barriers and government related factors. In the first group low level of awareness on green products by the actors of the construction sector (96\%), lack of green labels for construction materials, products and services (89\%) and no existence of a national green building certification system $(88 \%)$ in the country were the main cited barriers. In this same group while the statements "size of market for green products in Nepal is small and lack of demand for green products" obtained about $65 \%$ of the combined strong agree and agree opinion, almost a third of the respondents (33\%) have marked the option strong disagree and 30\% the combined options (strong disagree and disagree) for the second statement. These interesting results could be seen as an indication that a relatively important marked for green housing products do exist in Nepal.

Figure 4 Barriers and Factors Hindering the Development and the use of Green Products and Services in the $\mathrm{SCs}$

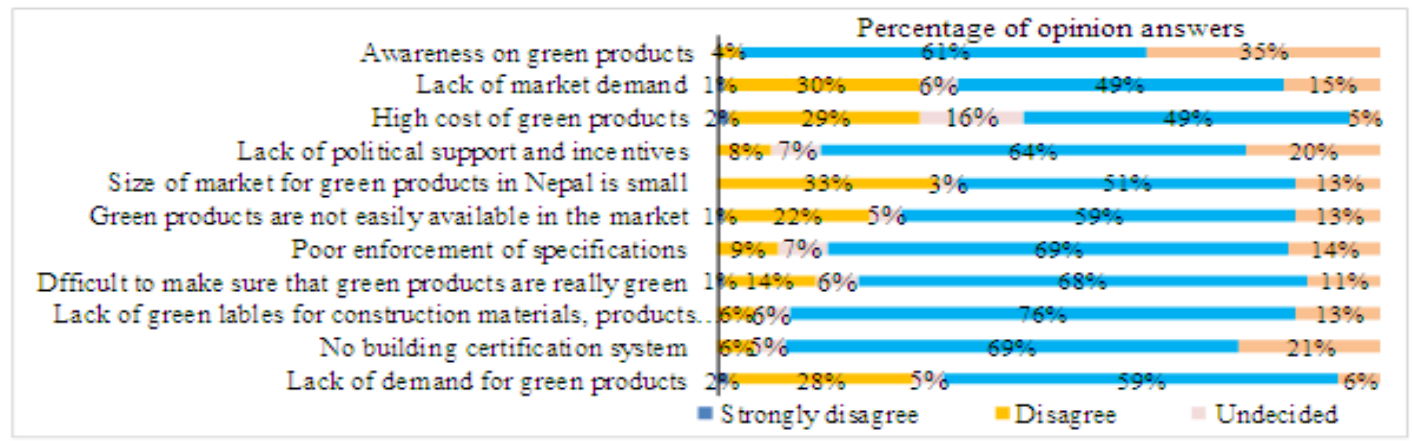

The absence of clear government policies to promote green buildings and green products $(95 \%)$ was the most important factor hindering the development of green practices and followed by the inexistence of government green building requirements and the lack of enforcement and awareness of the national policy on climate change (90\%). Lack of financial incentives $(86 \%)$, green issues are not incorporated into the existent national building code (83\%) and simplification of the existent procedures for buying and installing solar panels and other green features are the other factors mentioned by combined strong agree and agree opinions.

\subsubsection{Dedicated Staff for Dealing with Sustainable and Green Issues in the Company, Influence of the Green Issues in Selecting a Supplier and the Size of the Companies}

The majority of the contacted companies, $66 \%$ do not a have a special person employed to deal with green issues but $26 \%$ of the companies have a dedicate staff and/or a team dealing with green and sustainability issues in their SCs. $8 \%$ are not sure.. 
Green issues (Figure 5) is not or very little considered (40\% little importance and 21\% not sure) for the majority of the contacted companies in selecting their suppliers e). On the other hand $30 \%$ of the companies do considering green in selecting a supplier and $9 \%$ also see green issue as a critical factor in this selection. The fact that $39 \%$ of all companies consider green issues in selecting their suppliers is a very positive result and once more is in line with the previous results that have showed the existence of a green market for the build construction sector and that companies are trying to adapt themselves to the new development of this market.

Per city, $88 \%$ of the companies in Dahran do not have a particular person or team responsible for environmental issues and only $4 \%$ of the local companies consider green issues in selecting suppliers followed by Pokhara and Kathmandu. The fact that Dahran is small city compared to Pokhara and Katmandu and the fact the most of the companies of the building construction sector are small countries may explain these results.

The result of the ANOVA showed that the size of the company influences the existence of a dedicated person to manage and/or deal with green issues within the companies SCs. When the results are broken down per size of the company $69 \%$ of the small companies do not have a special person to deal with environmental issues compared to $61 \%$ in large/medium companies.

Figure 5: Green issues in selecting a supplier

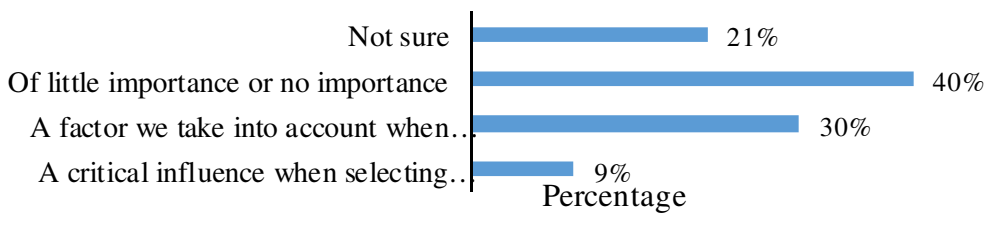

\section{Conclusions}

The research conducted in three cities of Nepal (Katmadu, Pokhara and Dahran) during the year of 2015 with 109 companies and six public and civil organisations linked to the building construction sector showed that the Nepalese construction sector is fragmented and made up of a majority of small companies. Most of these companies are manufacturing companies delivering diverse types of construction products, followed by construction and/or contractor companies involved with the on-site construction of houses. The vast majority of managers and/or owners of these companies are males, young (21-40 years old), well-educated with a good understanding of the meaning and definitions of the terms SCs and SCM and give high importance to the local market changes in relation to the ne green preferences and demands of the clients and suppliers.

Companies create SCs in first instance to increase customer satisfaction, to build trust among the suppliers and to reduce the delivery time of products and services to the site construction. Many actors were active in these SCs such as contractor, constructor, sub-contractors, designers, clients, suppliers and distributors (retailers). Using the classification purposed by Mentzer, et al [4] we have tentatively broadly classified these SCs as middle type length. The management of these SCs was highly affected in first place by the existence of poor information and communication technology in the companies followed by lack of planning skills and by the fast change of the construction market in relation to the clients green preferences and demands. Small and medium enterprises are those most affected by these factors. 
The majority of the companies (55\%) all sizes included, had a dedicated person to manage their SCs but in $65 \%$ of them these persons are not responsible for the final decision to buy products and materials. This decision especially in the SMEs relies in the hands of the owner of the companies. Companies build up relationships with their suppliers to maintain long-term sales with their suppliers, to retain them and to keep a close contact between suppliers and clients. Mutual trust and cost reduction are the two most important factor to guarantee a successful relationship. Inadequate information sharing defined as lack of communication among the suppliers, constraints resources, and lack of integration between those who design and those who construct/deliver the most important barriers to keep and improve these relationships. The existing relationships within these SCs are complex involving coordination, strategic and collaborative partnerships. The existence of few big construction companies in Nepal with the fact that most of these supplies chains were identified as middle length type may help to explain these results. Although commercial and profitability issues are important reasons and factors to build up and guarantee the success of the relationships, mutual trust was also found to be the most important elements to keep and steer these relationships. While the majority of the respondents have a very good understand of the concepts, advantages and the attributes a product, material or service need to have to be considered green, more than $60 \%$ of these respondents wrongly think that green building certification and the use of green products are compulsory instrument and actions. Market forces such as corporate environmental and social responsibility, attracting and retaining clients, and improving the company's image were driving companies to adopt green practices, products and services in their SCM. Low level of awareness (knowledge) about the use green products by the actors of the building construction SCs together with the lack of green labels for construction materials, products and services were the most important barriers and the absence of clear government policies to promote green buildings and green products followed by the inexistence of government green building requirements and the lack of enforcement and awareness of the national policy on climate change the most important factors hindering the development and the use of the green practices and products in these SCs.

The majority of the companies were using one or more green practice or technology related to waste and water reduction, environmentally friend energy sources and green procurement. Large and medium size companies are those using more of these practices. Only 22 of all contacted companies were found to be producing or selling green products, materials and/or services including solar panels, renewable energy and solar water heating appliances, high insulate UPVC windows; rain water harvest products and services and hollow block cements. The majority of the companies $(66 \%)$ do not a have a special person employed to deal with green issues and $39 \%$ of them take into account green issues in selecting a supplier. Per city, $88 \%$ of the companies in Dahran do not have a particular person or team responsible for environmental issues and only $4 \%$ of the local companies consider green issues in selecting suppliers. The size of the company influences the presence of this special person to deal with green issues and also the inclusion of green issues in selecting their suppliers. Small companies are the ones who most often do not have this person and do not take into account green issues in selecting their suppliers. In general $39 \%$ of the companies consider green issues in selecting suppliers while $61 \%$ (majority) give little importance or no importance to the green issues or are not sure.

As a final conclusion we can say that Nepalese companies of the construction sector are already part of the globalised economy and as such they have many of theirs suppliers abroad which is putting pressure on these companies to improve their actual week information, communication, market skills and capacity on developing green products/services to better face the competition of the local and international competitors. These companies and in special the SMEs needs external support on these issues. Companies are aware of the fast market change development in relation 
to the new green preferences and demands of the local consumers and are actively trying to adapt their SCM practices with this new scenario. As result of this pressure several companies are already producing green products and using green practices within their production processes. They also expect that the Nepalese government could play a more active role in helping to strength the sustainability of the housing sector by developing clear policies to promote the advantages of the green buildings and green products, incorporating green energy performance issues into the national building code, simplifying the current complicated administrative procedures for buying and installing solar panels and renewable energy appliances and finally develop national financial incentives schemes for green construction products and materials.

The findings of this research support the actual view that promoting sustainable consumption and production along the SCs of a sector is most effective strategy to achieve the objectives of sustainable development and to promote the use of green principles in a sector. As these results have showed many companies are already adopting green practices and including green issues in selecting their suppliers. If more and more company also adopt these practices into their SCM and embed green issues into the selection of their suppliers, in the long term the sector will improve its sustainability.

As the research used a non-probabilistic sampling approach which implied a relatively small sample size, we are aware that these results cannot be generalised but are more likely to be a representation of the situation of the involved cities at the moment the data was collected. We also acknowledge that some choices made in the sampling method such as targeting the manager or owners of the companies to answer the questionnaire and the need to translate them during the process of application (especially with many small companies) may have influenced the results.

\section{ACKNOWLEDGEMENTS}

The authors would like to thank Mr Padma Sunder Joshi, general manager of UN Habitat Nepal, Dr. Santos Shrestha, project manager for their support in planning and implementing the research and Mrs. Sharon Welsh our colleague from IHS, for the editing work

\section{REFERENCES}

[1] R. Antink, C. Garrigan, M. Bonetti and R. Westaway, (2014) Greening the building supply chain sustainable buildings and climate initiative. Nairobi: United Nations Environment Programme.

[2] A. Ross. (2011) Supply chain management in an uncertain economic climate: A UK perspective. Construction Innovation 11(1), pp. 5-13.

[3] R. Handfield. (2002) Reducing the impact of disruptions to the supply chain. Cary: SAS Institute

[4] J. T. Mentzer, W. DeWitt, J. S. Keebler, S. Min, N. W. Nix, C. D. Smith and Z. G. Zacharia. (2001) Defining supply chain management. Journal of Business Logistics 22(2), pp. 1-25.

[5] H. Quesada, R. Gazo and S. Sanchez. (2012) Critical factors affecting supply chain management: A Case study in the US pallet industry, Rijeka: INTECH Open Access Publisher

[6] de Sousa Jabbour, Ana B.L., A. G. Alves Filho, A. B. N. Viana and C. J. C. Jabbour. (2011) Factors affecting the adoption of supply chain management practices: Evidence from the Brazilian electroelectronic sector. IIMB Management Review 23(4), pp. 208-222.

[7] M. Tseng, J. H. Chiang and L. W. Lan. (2009) Selection of optimal supplier in supply chain management strategy with analytic network process and choquet integral. Comput. Ind. Eng. 57(1), pp. 330-340.

[8] S. Petrovic-Lazarevic, M. Matanda and R. Worthy. (2006) Supply chain management in building and construction industry: Case of Australian residential sector, Melbourne: Monash University

[9] S. Renko. (2011) Vertical collaboration in the supply chain, Rijeka: INTECH Open Access Publisher 
[10] D. J. Bowersox, D. J. Closs and M. B. Cooper. (2002) supply chain logistics management 2, New York: McGraw-Hill

[11] Ö Koçtaş and Ö B. Tek. (2013) Construction supply chains: A Proposal to develop a new conceptual model, Cappadocia: International Logistics and Supply Chain Congress.

[12] M. Charter, A. Kielkiewicz-Young, A. Young and A. Hughes. (2001) supply chain strategy and evaluation, London: University College.

[13] W. J. O'Brien, C. T. Formoso, V. Ruben and K. London. (2008) construction supply chain management handbook, Boca Raton: CRC press.

[14] S. Singh. (2010) Study of green supply chain management practices in the Indian manufacturing industries, ISEM Society.

[15] M. Prasad, (2014) Communicating green products to consumers in India to promote sustainable consumption. Mumbai: Green purchasing network India.

[16] A. Wilson and M. Piepkorn. (2008) Green building products: The Greenspec guide to residential building materials, London: New Society Publishers.

[17] M. Rajbhandari, (2006) Nepal sustainable building design and construction in Nepal with reference to urban housing: issues and proposed measures. Tokyo: IIBH.

\section{Authors}

Dr. Ogenis Brilhante (PhD):Senior expert Environment Planning, Green City and Infrastructure Management with the Institute for Housing and Urban Development Studies (IHS), Erasmus University, Rotterdam (EUR)

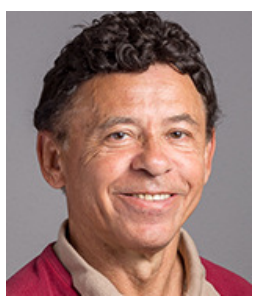

